\title{
Nickel Nanofibers Manufactured via Sol-Gel and Electrospinning Processes for Electrically Conductive Adhesive Applications
}

\author{
Darunee Aussawasathien ${ }^{1}$ and Erol Sancaktar ${ }^{2, *}$ \\ 1 National Metal and Materials Technology Center, 114 Thailand Science Park, Paholyothin Rd., Klong 1, \\ Klong Luang, Pathumthani 12120, Thailand; daruneea@mtec.or.th \\ 2 Department of Polymer Engineering, The University of Akron, Akron, OH 44325-0301, USA \\ * Correspondence: erol@uakron.edu
}

Received: 10 March 2020; Accepted: 9 April 2020; Published: 13 April 2020

\begin{abstract}
The electrospun fibers of poly(vinyl pyrrolidone) (PVP)-nickel acetate $\left(\mathrm{Ni}\left(\mathrm{CH}_{3} \mathrm{COO}\right)_{2} \cdot 4 \mathrm{H}_{2} \mathrm{O}\right)$ composite were successfully prepared by using sol-gel processing and electrospinning technique. Nickel oxide $(\mathrm{NiO})$ nanofibers were obtained afterwards by high temperature calcinations of the precursor fibers, $\mathrm{PVP} / \mathrm{Ni}$ acetate composite nanofibers, at $700^{\circ} \mathrm{C}$ for $10 \mathrm{~h}$. Following with the reduction of $\mathrm{NiO}$ nanofibers at $400{ }^{\circ} \mathrm{C}$ using hydrogen gas $\left(\mathrm{H}_{2}\right)$ under inert atmosphere, the metallic nickel $(\mathrm{Ni})$ nanofibers were subsequently produced. In addition, as-prepared Ni nanofibers were chemically coated with silver (Ag) nanoparticles to enhance their electrical property and prevent the surface oxidation. The characteristics of as-prepared fibers, such as surface morphology, fiber diameters, purity, the amount of $\mathrm{NiO}$ nanofibers, and metal crystallinity, were determined using a scanning electron microscope (SEM), a Fourier transform infrared spectrometer (FT-IR), a thermogravimetric analyzer (TGA), and a wide-angle x-ray diffractometer (WAXD). The volume resistivity of epoxy nanocomposite filled with Ag-coated short Ni nanofibers was lower than the one containing short $\mathrm{Ni}$ nanofibers with no coating due to the synergetic effect of $\mathrm{Ag}$ nanoparticles created during the coating process. We also demonstrated that the volume resistivity of epoxy nanocomposite filled with $\mathrm{Ni}$ nanofibers could be dramatically decreased by using Ni nanofibers in the non-woven mat form due to their small fiber diameter and high fiber aspect ratio, which yield a high specific surface area, and high interconnecting network.
\end{abstract}

Keywords: nickel nanofibers; electrically conductive adhesive; electrospinning; sol-gel process; silver coating; volume resistivity

\section{Introduction}

There has been a lot of work devoted to the electrospinning process and the use of carbon nanofibers in epoxy. Aussawasathien and Sancaktar [1] reported that epoxy nanocomposites containing high fiber aspect ratio electrospun carbon nanofibers (ECNF) in the non-woven mat form had higher mechanical properties than those filled with short ECNFs. This was attributed to the non-woven mat inducing homogeneity in the epoxy nanocomposite, as well as the additional mechanical advantage acquired due to inter-, as well as intra-, fiber entanglements and friction. The values of storage, loss, and Young's moduli, as well as the ultimate tensile strength, increased for these nanocomposites, while toughness and flexural strength decreased in comparison to the neat epoxy resin and the short ECNF-epoxy nanocomposites. Their work [2] also showed that non-woven ECNF mat presence in the nanocomposite composite increased the heat flow and reaction rates and conversion at initial cure stage when compared with the neat epoxy resin. These values also exhibited a maximum at a certain 
curing temperature and time combination in the presence of the non-woven mat. The amount of ECNF mat also affected the cure reaction of the epoxy nanocomposite. The ECNF mat-epoxy composite exhibited lower activation energy than the neat epoxy system at the initial stages of cure and the cure reaction was retarded at high ECNF mat loading due to the hindering effect of the ECNF mat to the diffusion of the curing agent, leading to low crosslinking efficiency. Furthermore, the amount of epoxy and hardener decreased at high ECNF contents. On the other hand, even though the curing efficiency for the epoxy nanocomposites decreased at high ECNF mat contents, their glass transition temperature $\left(\mathrm{T}_{\mathrm{g}}\right)$ was still high due to the high strength of the ECNF mat. Aussawasathien and Sancaktar [3] achieved improved conductivities by preparing ECNF from in-situ Ag-Polyacrylonitrile (PAN) solution and by coating Ag on the ECNF mat. It was found that the Ag-modified ECNF from both methods yielded higher electrical conductivity than the neat ECNF due to the synergetic effect achieved with the presence of Ag nanoparticles.

Despite the considerable amount of research work done on organic-based ECNF, little attention has been paid to inorganic nanofibers. Various ceramic metal oxide fibers (with diameters between 200 and $400 \mathrm{~nm}$ ) have been synthesized by high temperature calcinations of nanofibers made of organic-inorganic composite precursor by electrospinning. It was generally observed that the calcination temperature has a great influence on both the crystalline phase and the surface morphology of these fibers [4,5]. On the other hand, there has not been much attention paid to metal nanofibers fabricated using organic-inorganic composite precursors via the electrospinning technique, and their use as fillers in conductive adhesives and/or polymers in general.

Electrospinning has been used to produce mesoporous metal oxide fibers with diameters in the nanometer to submicron range by using electrospun fibers of polymer-inorganic composite as the precursor [6-8]. The process involves the following steps: (1) preparation of a sol with suitable inorganic precursor (metal complex) and polymer contents, and achieving the right rheology for electrospinning; (2) spinning of the solution to obtain fibers of polymer-inorganic composites; (3) calcinations of the composite fibers to obtain final oxide fibers. Since most of the metals form complex structures as metal acetate, which can be soluble in water and alcohol, the polymers used in the preparation of polymer-inorganic precursor have to be soluble in such solvents as well such as polyvinyl alcohol (PVA) and poly(vinyl pyrrolidone) (PVP).

Nickel oxide $(\mathrm{NiO})$ is a very important material extensively used in catalysis, battery cathodes, gas sensor, electrochromic films, and magnetic materials. The preparation and characterization of $\mathrm{NiO}$ nanofibers via an electrospinning technique have been reported [9] using polyvinyl alcohol (PVA)/Ni acetate precursor solution. However, to our knowledge, there have been no reports on the preparation of electrospun Ni nanofibers using $\mathrm{PVP} / \mathrm{Ni}$ acetate composites. The reduction in $\mathrm{NiO}$ with helium-hydrogen gas mixtures in the range of $300-400{ }^{\circ} \mathrm{C}$ can be carried out by the following schematic reaction [10]:

$$
\mathrm{NiO}(\mathrm{s})+\mathrm{H}_{2}(\mathrm{~g})=\mathrm{Ni}(\mathrm{s})+\mathrm{H}_{2} \mathrm{O}(\mathrm{g})
$$

Since Ni has high conductivity, it is mainly used in polymer composites, such as in epoxy resin, in [11-14] to increase its conductivity. Furthermore, its magnetic property allows its alignment in (epoxy) resin, especially in uncured resin in liquid form using magnetic fields to manufacture anisotropically conductive adhesives [15].

The work reported here involves the preparation of Ni nanofibers by using sol-gel processing and the electrospinning technique. Initially, nanofibers of PVP/Ni acetate composite are obtained, which are converted to porous nanofibers of $\mathrm{NiO}$ after calcination. The $\mathrm{NiO}$ nanofibers are then reduced to Ni nanofibers with similar characteristics of fiber diameters, brittleness, and beaded structure, as with the NiO nanofibers. The as-prepared Ni nanofibers are also chemically coated with silver $(\mathrm{Ag})$ nanoparticles to enhance their electrical property and prevent the surface oxidation. Finally, the volume resistivity $\left(\rho_{\mathrm{v}}\right)$ values for nanofiber-epoxy nanocomposites of Ag-coated $\mathrm{Ni}$ and uncoated $\mathrm{Ni}$ as well as Ni nanofibers in the non-woven mat form are evaluated to assess the conduction efficiency of the $\mathrm{Ni}$ nanofibers fabricated using organic-inorganic composite precursors via the electrospinning technique. 


\section{Materials and Methods}

\subsection{Ni Nanofibers via Electrospinning}

A total of $2.2 \mathrm{~g}$ of $10.0 \mathrm{wt} \%$ PVP (Mw $\approx 120,000$, GAF Chemical Corporation) solution in mixed solvent of distilled water and ethanol (1:1) was dropped slowly into the aqueous solution of $\mathrm{Ni}$ acetate (M.W. $=176.80)$ supplied from Strem Chemicals, Inc. $\left(1.0 \mathrm{~g} \mathrm{Ni}\left(\mathrm{CH}_{3} \mathrm{COO}\right)_{2} \cdot 4 \mathrm{H}_{2} \mathrm{O}\right.$ and $\left.3.0 \mathrm{~g} \mathrm{H}_{2} \mathrm{O}\right)$ at $60{ }^{\circ} \mathrm{C}$ under mechanical stirring for $5 \mathrm{~h}$. A clear green viscous gel solution of $\mathrm{PVP} / \mathrm{Ni}$ acetate composite was obtained and then filled in the glass pipette for electrospinning. The sol solution was kept stirring and warm in order to prevent the precipitation of the metal complex. A voltage of $30 \mathrm{kV}$ was applied to the solution via copper wire with the gap distance between the tip of the pipette (diameter $\approx 1.25 \mathrm{~mm}$ ) and the collector kept at about $30 \mathrm{~cm}$. A dense web of fibers was collected on a piece of paper placed on grounded aluminum (Al) plate serving as the counter electrode. The collected fibers were dried overnight at $60^{\circ} \mathrm{C}$ under vacuum before calcination in a high temperature furnace at $700{ }^{\circ} \mathrm{C}$ at a rate of $10^{\circ} \mathrm{C} \mathrm{min}{ }^{-1}$ for $10 \mathrm{~h}$ to produce $\mathrm{NiO}$ nanofibers. The reduction of $\mathrm{NiO}$ nanofibers was carried out in a closed furnace with the mixture of $\mathrm{N}_{2}$ and $\mathrm{H}_{2}$ gas flow at $400{ }^{\circ} \mathrm{C}$ for $1 \mathrm{~h}$. The reduced metal was slowly cooled in the furnace, under a flow of $\mathrm{N}_{2}$ gas to prevent reoxidation until the furnace was allowed to cool to room temperature [16].

\subsection{Ag-Coated Ni Nanofibers}

In total, $0.25 \mathrm{~g}$ of nanofiber mat was admixed with $25 \mathrm{~mL}$ of ethylene glycol (EG) supplied from Fisher Scientific and mechanically stirred at $125^{\circ} \mathrm{C}$. A total of $0.01 \mathrm{~g}$ of silver nitrate $\left(\mathrm{AgNO}_{3}\right.$, from Fisher Scientific) in $25 \mathrm{~mL}$ of EG, $0.375 \mathrm{~g}$ of $\mathrm{AgNO}_{3}$ in $25 \mathrm{~mL}$ of $\mathrm{EG}$, and $0.375 \mathrm{~g}$ of PVP $\left(\mathrm{M}_{\mathrm{w}}=30,000\right.$ provided by BASF Chemicals Co.) in $25 \mathrm{~mL}$ of EG $(1.5 \%(\mathrm{w} / \mathrm{v}))$ were all added slowly in hot solution, respectively. The reaction temperature was kept at $125^{\circ} \mathrm{C}$ for $4 \mathrm{~h}$ [9].

\subsection{Preparation of Nanocomposites with Epoxy}

Composite specimens were prepared from non-woven Ni nanofiber mat impregnated with epoxy resin. In total, $89.0 \mathrm{wt} \%$ epoxy resin (Epon $815 \mathrm{C}$, from Shell Chemicals) and $11.0 \mathrm{wt} \%$ diethylenetriamaine (DETA, Epikure 3223 from Resolution Performance Products) were mechanically mixed for $10 \mathrm{~min}$ prior to impregnation. In case of short nanofiber-epoxy nanocomposites, each conductive nanofiber material was ground manually using a mortar and then sonicated (Sonicating bath, Branson 2510 from American Laboratory Trading LLC) with $89 \mathrm{wt} \%$ epoxy resin (Epon815C) for $1 \mathrm{~h}$ at room temperature before manually mixing with $11 \mathrm{wt} \%$ DETA (Epikure 3223) for $10 \mathrm{~min}$. The cure reaction was done at $150{ }^{\circ} \mathrm{C}$ for $30 \mathrm{~min}$ under compression molding at $2000 \mathrm{psi}$. The sample was allowed to cool slowly to room temperature.

The $w t \%$ of fiber mat in epoxy nanocomposites can be calculated using Equation (2):

$$
\mathrm{w} t \% \text { of fiber mat }=\left(\mathrm{W}_{\mathrm{f}} \times 100\right) /\left(\mathrm{W}_{\mathrm{t}}-\mathrm{W}_{\mathrm{f}}\right)
$$

where $\mathrm{W}_{\mathrm{f}}$ is the weight of fiber mat before curing, and $\mathrm{W}_{\mathrm{t}}$ is the total weight of fiber mat-epoxy nanocomposite after curing. The vol\% of fiber mat in epoxy nanocomposites can also be obtained using Equation (3):

$$
\mathrm{vol} \% \text { of fiber mat }=\left(\mathrm{V}_{\mathrm{f}} \times 100\right) /\left(\mathrm{V}_{\mathrm{m}}\right)
$$

where $V_{\mathrm{f}}$ is the volume of fiber mat before curing determined from the bulk density and weight of fiber fabrics with the controlled size and shape (rectangular mat), and $V_{m}$ is the volume of epoxy matrix assuming that the densities of epoxy resin and curing agent are about same and amount and that epoxy resin is much higher than curing agent. Note that the density of fiber mat can be computed from Equation (4):

$$
\text { bulk density of fiber mat }=\mathrm{m} / \mathrm{V}
$$


where $m$ is the weight of fiber mat, and $V$ is the volume of fiber mat (width $\times$ length $\times$ thickness).

In case of short nanofiber-epoxy nanocomposites, each of the as-prepared conductive nanofiber materials was manually ground using a mortar and then sonicated (Sonicating bath, Branson 2510 from American Laboratory Trading LLC, Groton, CT, USA) with $89 \mathrm{wt} \%$ epoxy resin (Epon815C) for $1 \mathrm{~h}$ at room temperature before manually mixing with $11 \mathrm{wt} \%$ DETA (Epikure 3223) for $10 \mathrm{~min}$. The suspension before sonication showed a dark ring made up of the short nanofibers, in a white suspension made of the epoxy resin, indicating poor dispersion. After sonication, the improvement of dispersion was observed as a homogeneous solution.

\subsection{Characterization}

\subsubsection{Scanning Electron Microscope (SEM)}

The surface morphology of as-prepared samples was characterized using a Hitachi S-2150 SEM (Hitachi, Ltd., Chula Vista, CA, USA). Prior to characterization, the sample was attached onto an SEM stub using conducting tape and then sputter coated with a thin layer of Ag using Emitech K 575X Turbo Sputter Coater at $30 \mathrm{~mA}$ for $45 \mathrm{~s}$.

\subsubsection{Thermogravimetric Analyzer (TGA)}

A thermogravimetric analyzer (TGA 2050, TA Instruments, New Castle, DE, USA) was used to determine the degradation temperature and the amount of residue samples, which was based on the mass loss. The samples were carefully weighed to $7 \pm 2 \mathrm{mg}$ in a platinum pan and TGA scans were recorded at a rate of $20^{\circ} \mathrm{C} / \mathrm{min}$ under $\mathrm{O}_{2}$ and $\mathrm{N}_{2}$ atmospheres from room temperature to $900{ }^{\circ} \mathrm{C}$.

\subsubsection{Fourier Transform Infrared Spectrometer (FT-IR)}

The chemical structure of $\mathrm{PVP} / \mathrm{Ni}$ acetate nanofibers, $\mathrm{NiO}$ nanofibers, and Ni nanofibers was identified by FT-IR (Perkin Elmer 16PC, Perkin Elmer, Inc., Boston, MA, USA) with 16 scans per sample at a resolution of $4 \mathrm{~cm}^{-1}$. The sample was scanned in the range of $4400 \mathrm{to} 350 \mathrm{~cm}^{-1}$. Before running the experiment, the sample was pre-mixed with the potassium bromide $(\mathrm{KBr})$ powder (Thermo Electron Corporation, Madison, WI, USA) and then compressed to be a disc.

\subsubsection{Wide-Angle X-Ray Diffractometer (WAXD)}

X-ray diffraction scans of samples were obtained using a Bruker X-ray diffractometer (Bruker-AXS, Madison, WI, USA), at $40 \mathrm{kV}$ and $40 \mathrm{~mA}$. The WAXD device was equipped with a copper target tube, and a graphite crystal monochrometer. X-ray photographs were taken by using Ni-filtered $\mathrm{CuK} \alpha$ radiation $(\lambda=1.5418 \AA)$. X-ray diffraction was applied to determine the crystal structure. The scan range of $2 \theta$ was from $20^{\circ}-90^{\circ}$ for each sample.

\subsubsection{Resistivity}

The $\rho_{\mathrm{v}}$ of as-prepared nanofiber mats, short nanofibers, and epoxy nanocomposites filled with as-prepared conductive nanofiber materials was measured using the two-point probe method (ASTM standard F43-99) [17]. A 6514 System Electrometer (Keithley Instruments, Inc., Cleveland, OH, USA) was employed for the resistance measurements.

The $\rho_{\mathrm{v}}$, in $\Omega \cdot \mathrm{cm}$, was calculated using Equation (5), where R is the bulk resistance in $\Omega, W$ is the width, $\mathrm{H}$ is the height (thickness), and $\mathrm{L}$ is the length of specimens:

$$
\rho_{\mathrm{V}}=(\mathrm{R}) \cdot(\mathrm{WH} / \mathrm{L})
$$

Three specimens of each sample were tested, and the values were averaged. Aluminum foils were used to straddle the composite film at both ends on glass slides, as depicted in Figure 1. The adhesive solution, containing short nanofibers, was coated on the gap between these Al foil straps with a 
thickness of about $0.089 \mathrm{~mm}$. The composite film was cured in the oven at 120 and $150{ }^{\circ} \mathrm{C}$ for $3 \mathrm{~h}$. In case of the nanofiber mat sample and/or nanofiber mat-epoxy composite, two Al foil straps were placed as electrodes on each side of the conductive nanofiber mat and/or the composite film with a specific opening area. The thicknesses of the conductive nanofiber mat and the nanofiber mat-epoxy composite film prepared by using compression molding were $\sim 0.01-0.03$ and $\sim 0.10-0.15 \mathrm{~mm}$, respectively.

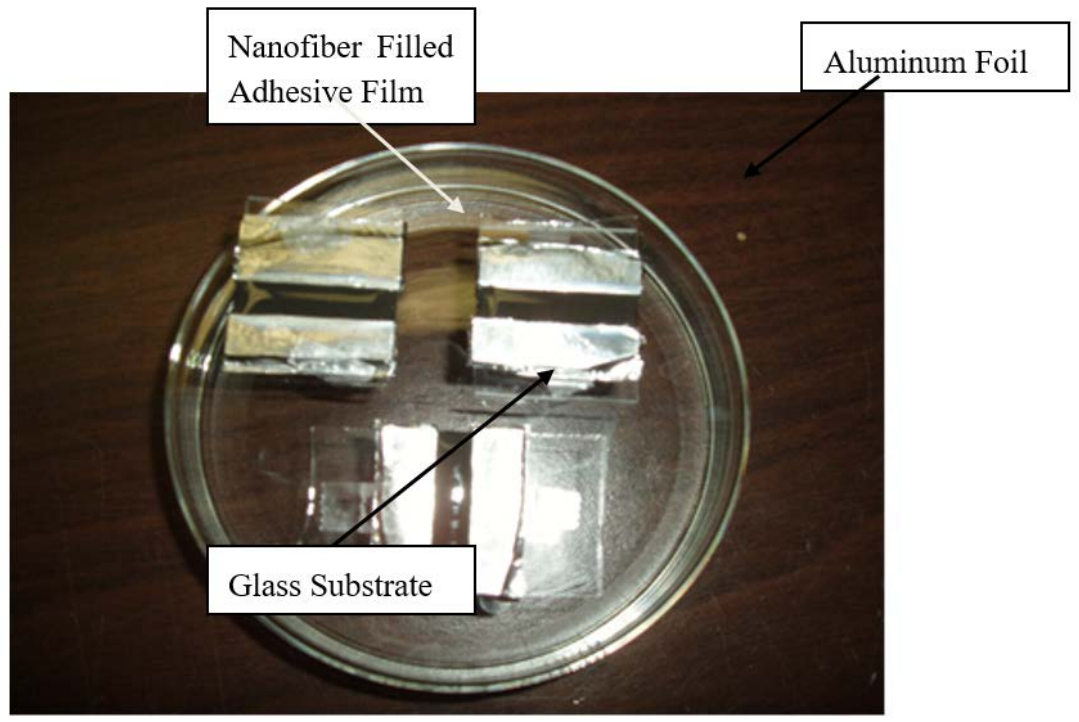

Figure 1. Samples used for the resistance measurement on epoxy adhesive films filled with conductive nanofiber materials.

\section{Results and Discussion}

The PVP/Ni acetate nanofiber mat prepared by electrospinning was light green in color due to the existence of Ni complex in the composite. After calcinations at high temperature and reduction with $\mathrm{H}_{2}$, the $\mathrm{NiO}$ and metallic Ni nanofiber mats were obtained, respectively, with a gray color (Figure 2).

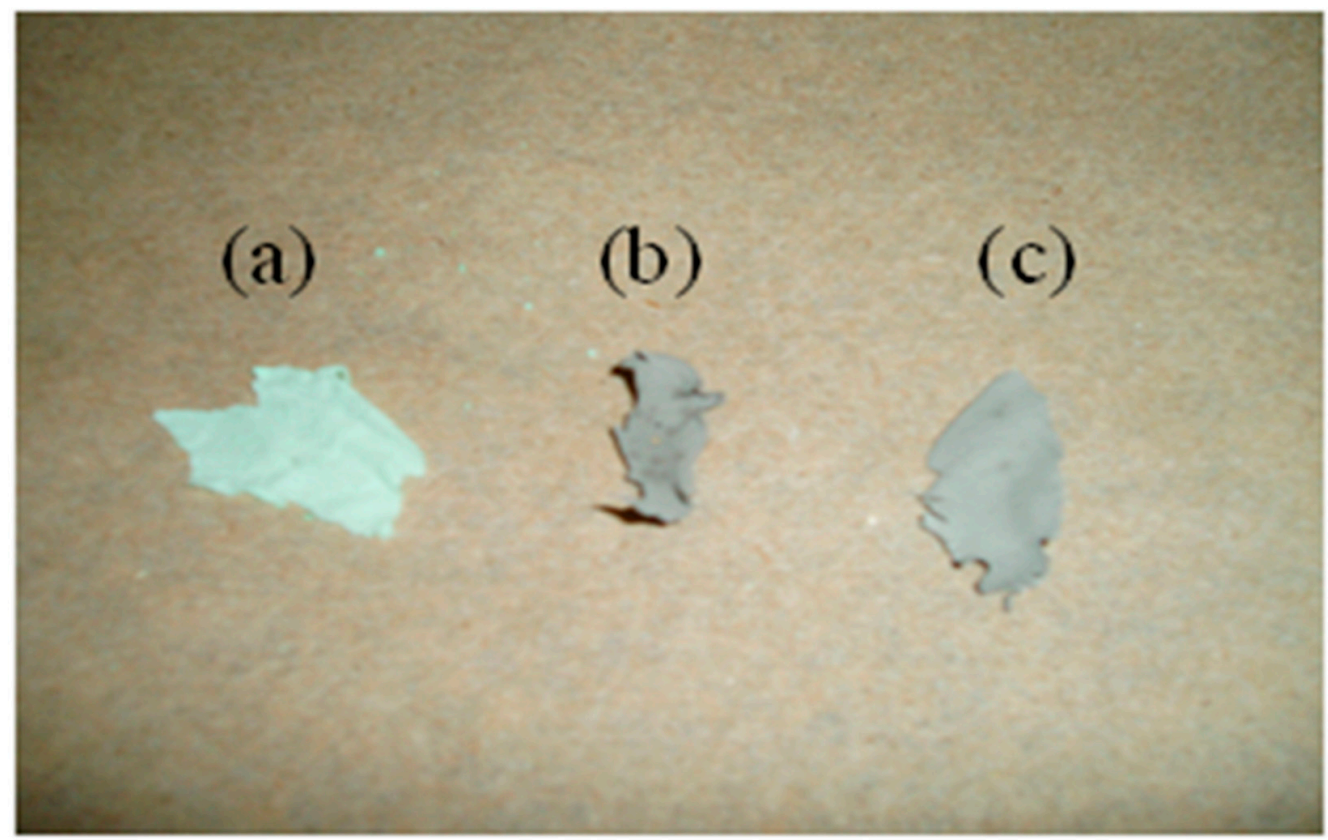

Figure 2. Nanofiber mats for: (a) poly(vinyl pyrrolidone) (PVP)/Ni acetate composite, (b) NiO after the calcination of $\mathrm{PVP} / \mathrm{Ni}$ acetate composite at $700{ }^{\circ} \mathrm{C}$, and (c) metallic $\mathrm{Ni}$ after the reduction of $\mathrm{NiO}$ with $\mathrm{H}_{2}$. 
The SEM method was utilized to determine the surface topology and the fiber diameter of as-prepared thin PVP/Ni acetate composite fibers, $\mathrm{NiO}$ nanofibers, and metallic Ni nanofibers, as demonstrated in Figures 3-5. It can be seen in Figure 3 that the surfaces of PVP/Ni acetate composite fibers was quite smooth due to their amorphous nature. The fiber diameter was in the range of 150-350 nm. Some beaded nanofibers were observed with varying sizes of beads. Upon calcination, the diameters of fibers became smaller, and the fiber surfaces were rougher (Figure 4) than the not calcinated examples, owing to the decomposition of PVP, the removal of $\mathrm{CH}_{3} \mathrm{COO}$ group of $\mathrm{Ni}$ acetate molecules in the $\mathrm{PVP} / \mathrm{Ni}$ acetate nanofiber composite, as well as the development of $\mathrm{NiO}$ crystal. The 50-150-nm diameter, porous, and brittle $\mathrm{NiO}$ nanofibers were obtained with some beads. In addition, $\mathrm{NiO}$ nanofibers were densely packed to each other due to the magnetic effect of $\mathrm{Ni}$ metal with the observation of some separate $\mathrm{NiO}$ nanofibers. Figure 5 demonstrates metallic Ni nanofibers with fiber characteristics similar to $\mathrm{NiO}$ nanofibers in terms of fiber diameters, beaded fibers, and brittleness.
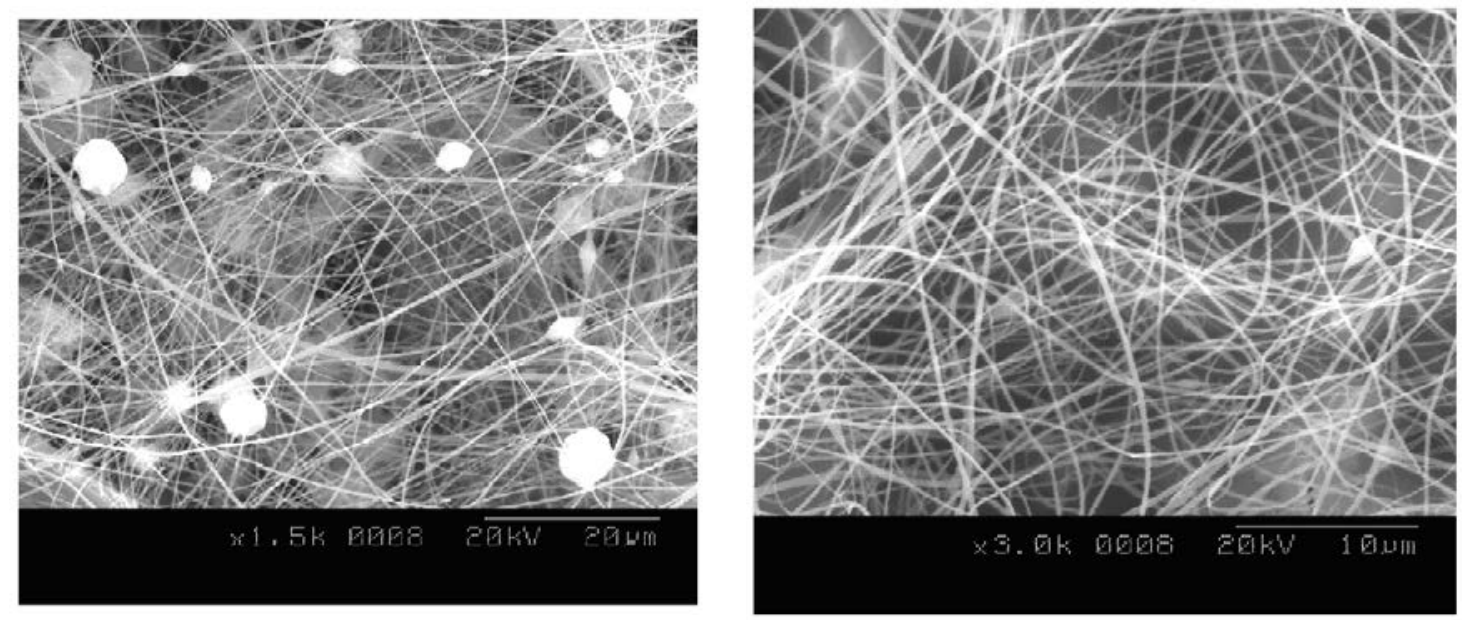

Figure 3. Scanning electron microscope (SEM) photographs of PVP/Ni acetate composite fibers: at low magnification (left), and at high magnification (right).
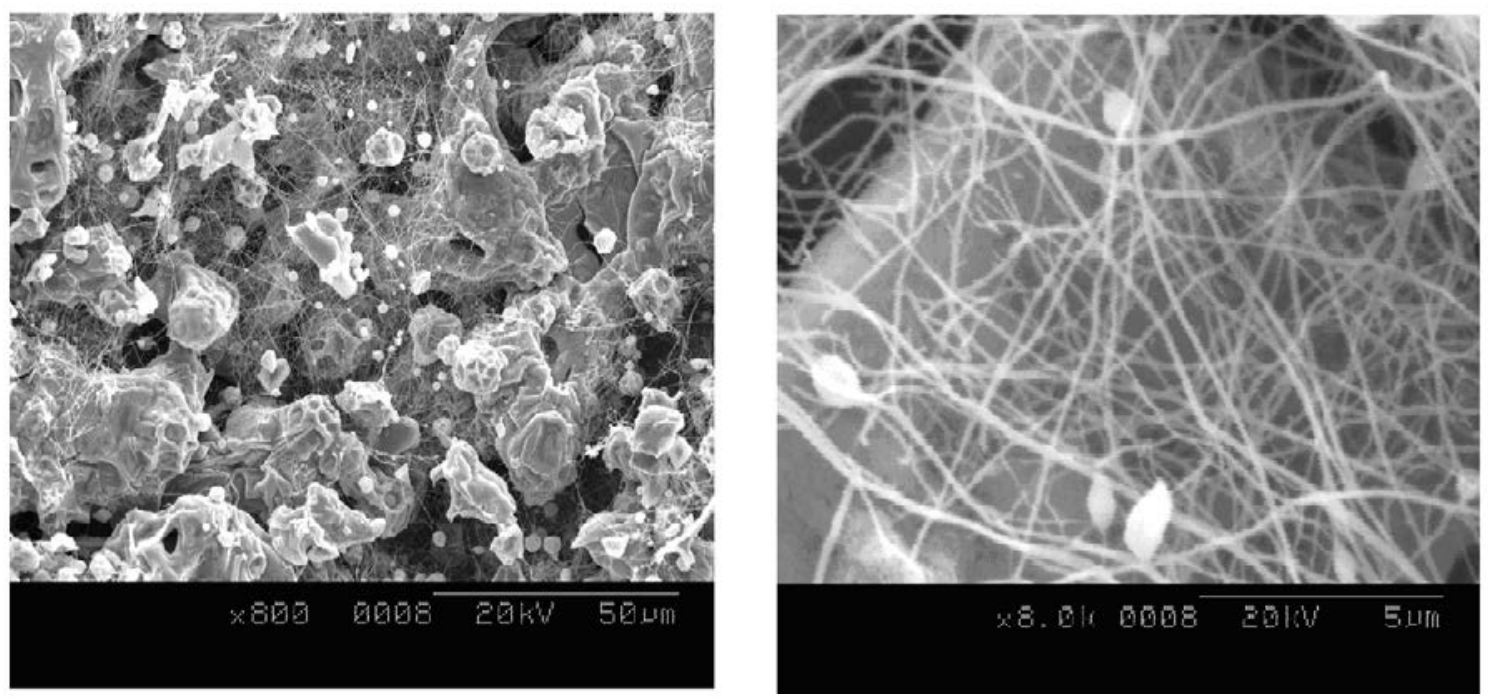

Figure 4. SEM photographs of $\mathrm{NiO}$ nanofibers: at low magnification (left), and at high magnification (right). 

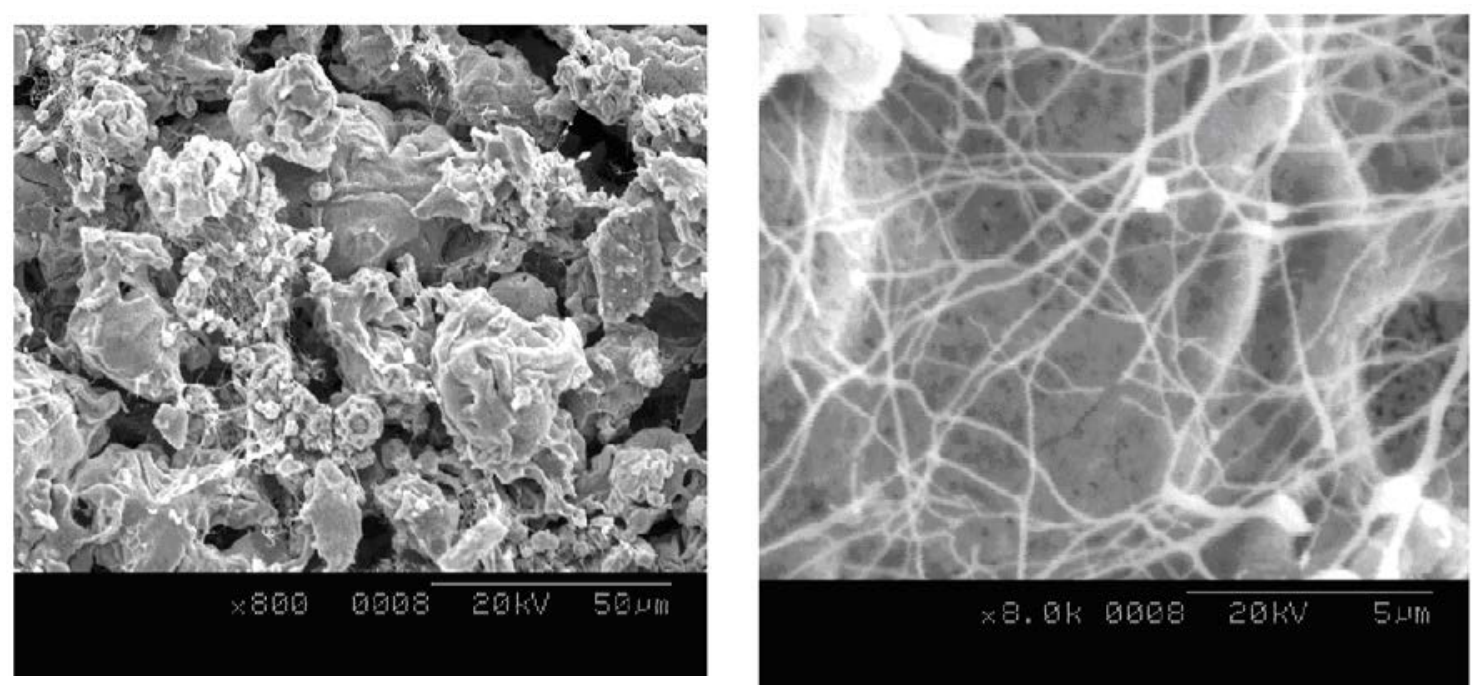

Figure 5. SEM photographs of Ni nanofibers: at low magnification (left), and at high magnification (right).

Grinding resulted in large chunks of metallic Ni nanofibers due to the magnetic effect of Ni metal (Figure 6). After chemically coating Ag on Ni nanofibers, the mat form was diminished due to the magnetic stirring during the reaction, yielding chunks of Ag-coated Ni nanofibers with various sizes (Figure 7). Even though the mat form has diminished in this process, the fiber-matrix interphase should increase in thickness due to the addition of $\mathrm{Ag}$, which also exists in particulate form on $\mathrm{Ni}$ nanofibers (Figure 7). Sancaktar and Zhang [18] showed that increases in interphase thickness reduces fiber end stress concentrations when in composite form with a polymer matrix.
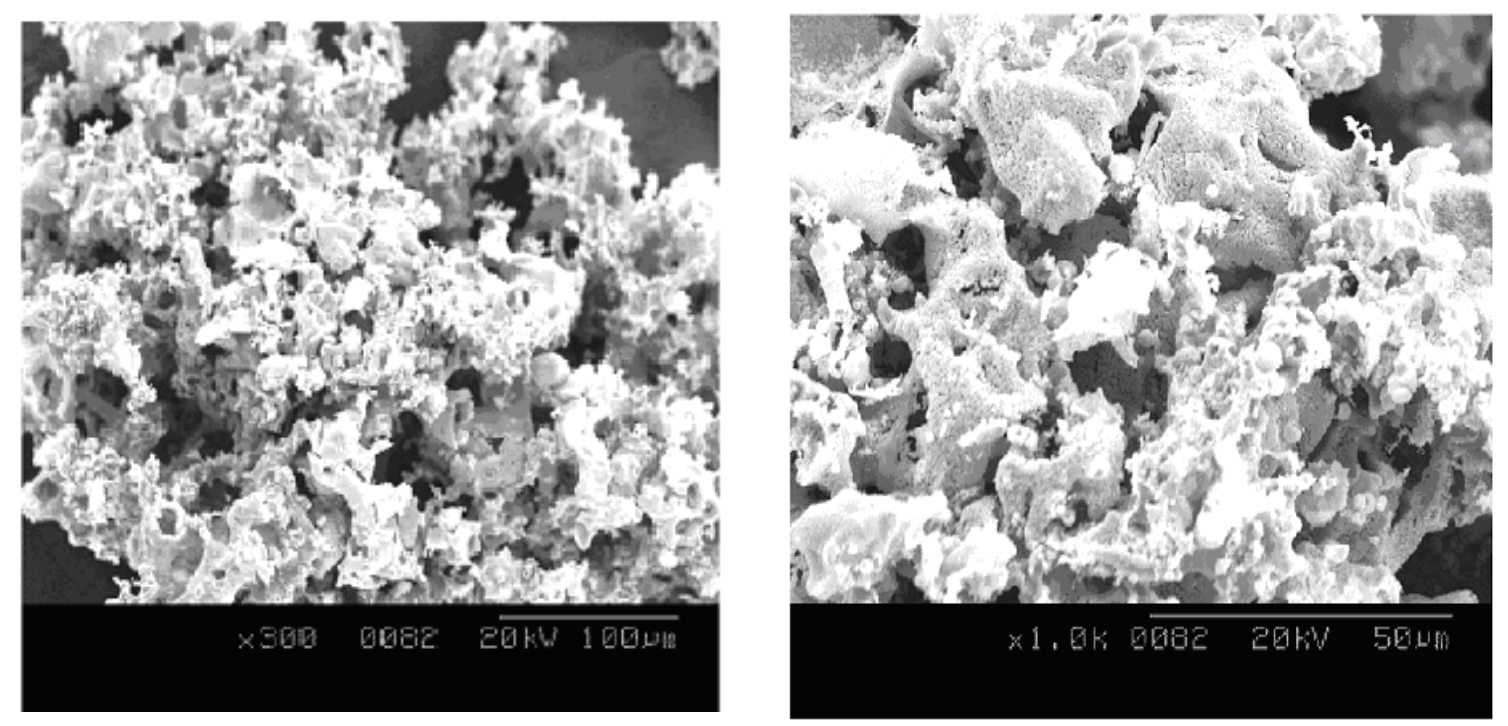

Figure 6. SEM photographs of Ni nanofibers after grinding with different magnifications: at low magnification (left), and at high magnification (right). 

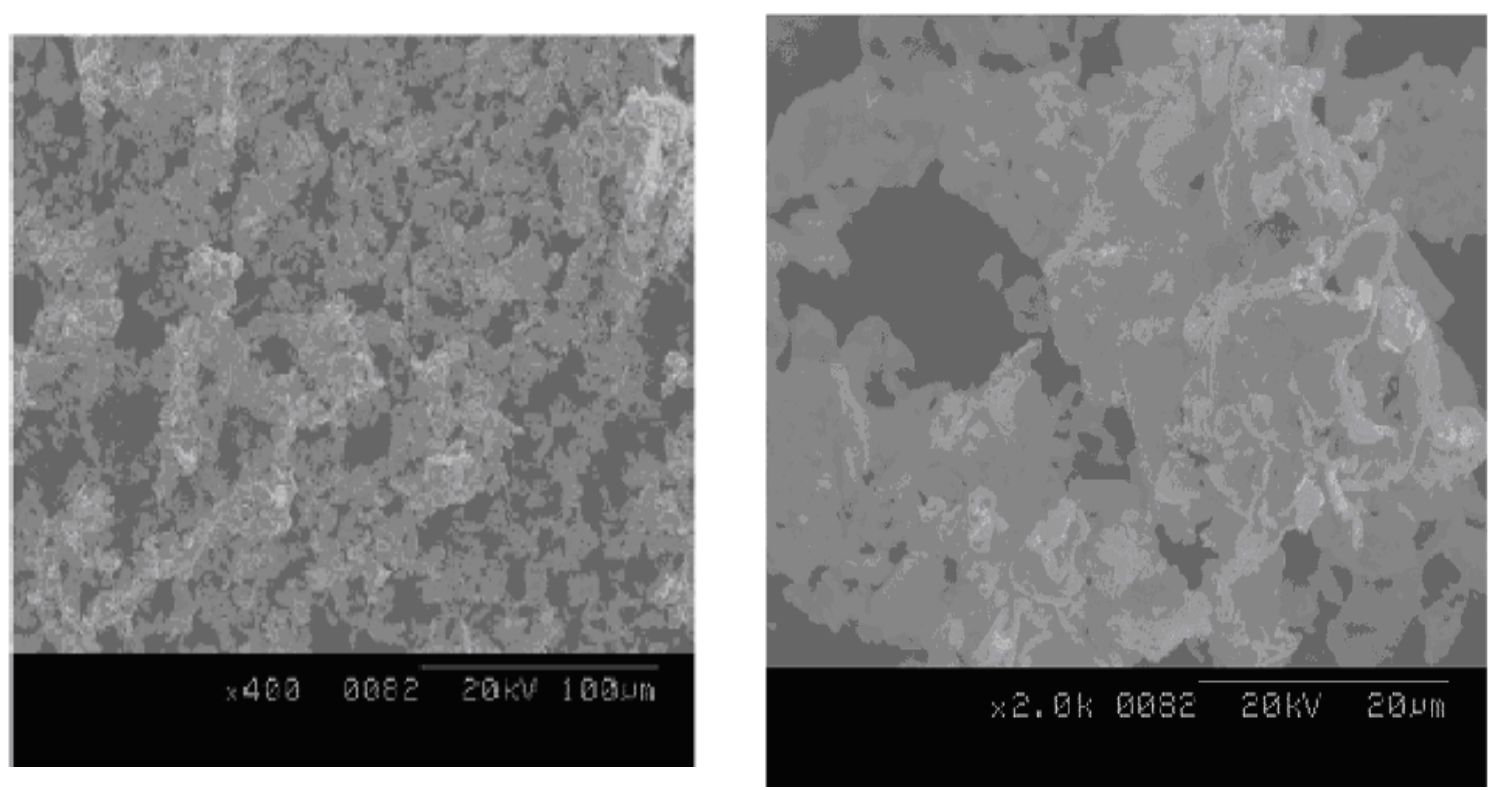

Figure 7. SEM photographs (with different magnifications) of Ni nanofibers after Ag coating for 4 h: at low magnification (left), and at high magnification (right).

The TGA thermogram in Figure 8 shows the weight loss for PVP/Ni acetate nanofiber composite at different temperatures $\left(25-900{ }^{\circ} \mathrm{C}\right)$. The weight loss at the $50-100{ }^{\circ} \mathrm{C}$ range could be attributed to the loss of moisture and trapped solvent (ethanol and water) used in preparing PVP/Ni acetate solution. The weight loss at about $280-620^{\circ} \mathrm{C}$ could be attributed to the decomposition of acetate along with the decomposition of PVP. It was clear from the TGA curve that all the PVP and organic group of Ni acetate were removed completely at about $625-650^{\circ} \mathrm{C}$. The oxidation reduction of the metallic residues began, at about $680{ }^{\circ} \mathrm{C}$ onward, to be a metal oxide composite phase since the \% weight increased due to the combination of $\mathrm{Ni}$ and $\mathrm{O}_{2}$.

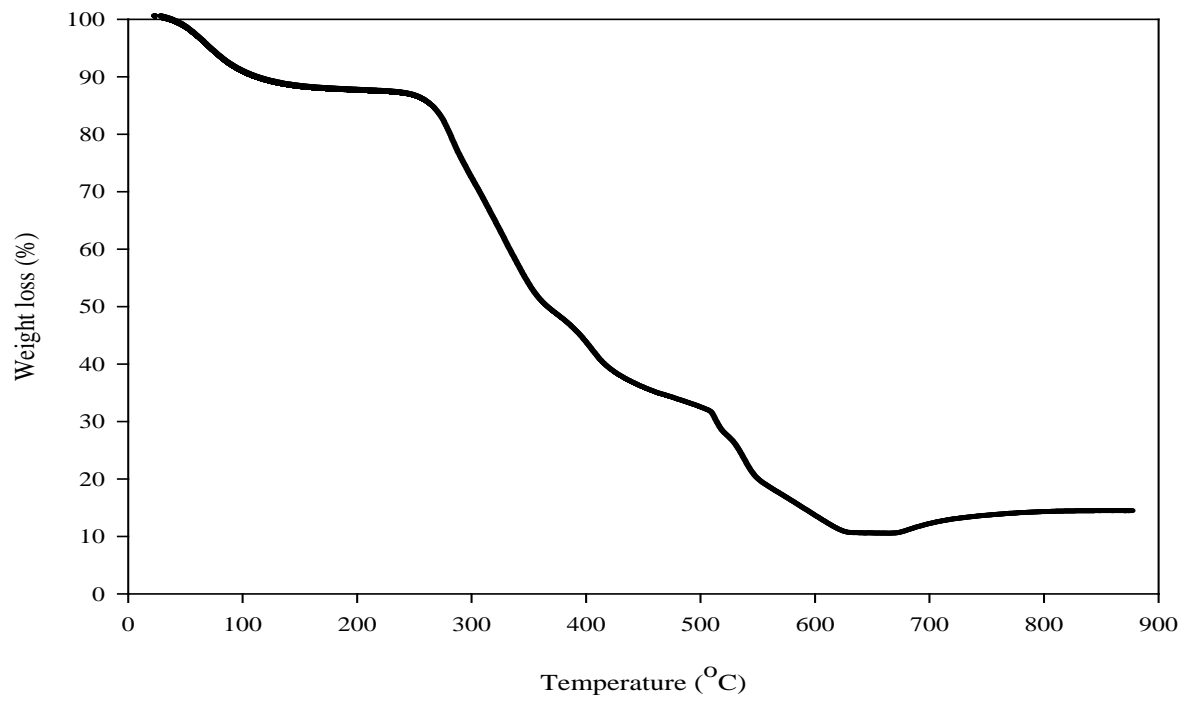

Figure 8. Thermogravimetric analyzer (TGA) thermogram obtained under $\mathrm{O}_{2}$ atmosphere at $20^{\circ} \mathrm{C} / \mathrm{min}$ scanning rate for $\mathrm{PVP} / \mathrm{Ni}$ acetate nanofibers.

Figure 9 shows the IR spectra for various fiber samples. From the TGA result, it can clearly be seen that all the organic molecules could be removed completely from the PVP/Ni acetate composite fibers after calcination. The peak around $475 \mathrm{~cm}^{-1}$, assigned to $v_{\mathrm{Ni}-\mathrm{O}}$ [19], is present, indicating that the fibers obtained at this temperature were pure inorganic species of $\mathrm{NiO}$. After the $\mathrm{H}_{2}$ reduction of 
$\mathrm{NiO}$ nanofibers, the characteristic peak of $\mathrm{NiO}$ species totally disappeared, indicating the absolute conversion of $\mathrm{NiO}$ nanofibers to Ni nanofibers.

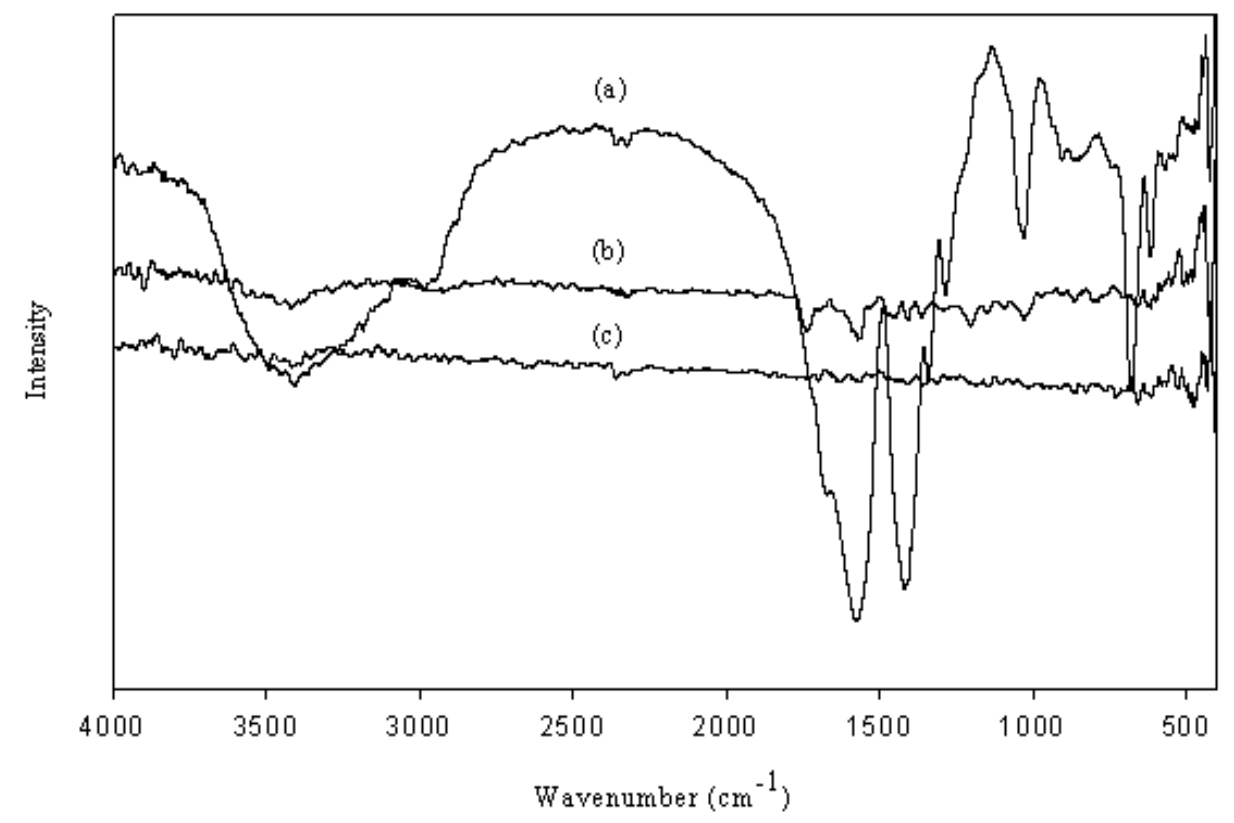

Figure 9. Fourier transform infrared spectrometer (FT-IR) spectra for: PVP/Ni acetate fiber mat (a), after calcination at $700{ }^{\circ} \mathrm{C}$ for $10 \mathrm{~h}(\mathbf{b})$, and after $\mathrm{H}_{2}$ reduction at $400{ }^{\circ} \mathrm{C}$ for $1 \mathrm{~h} \mathrm{(c).}$

Figure 10 gives the WAXD curves for various fiber samples. There is no peak observed for PVP/Ni acetate composite fibers (Figure 10a) due to the amorphous nature of this composite material. However, two reflection peaks, corresponding to pure cubic $\mathrm{NiO}$, appeared at about $2 \theta=37.2^{\circ}(\mathrm{Ni}[111])$, and $44^{\circ}$ ( $\mathrm{Ni}[200]$ ) [20] after PVP/Ni acetate composite fibers were calcinated (Figure 10b). Two clear peaks of $\mathrm{Ni}$ [111] and $\mathrm{Ni}$ [002] were obtained at peak positions of, approximately, $46^{\circ}, 53^{\circ}$, and $78^{\circ}$ [21] after the $\mathrm{H}_{2}$ reduction of $\mathrm{NiO}$ nanofibers. Furthermore, the reduction reaction was complete, as indicated by the disappearance of the characteristic peaks for the $\mathrm{NiO}$ nanofibers, leaving behind the pristine $\mathrm{Ni}$ nanofibers (Figure 10c).

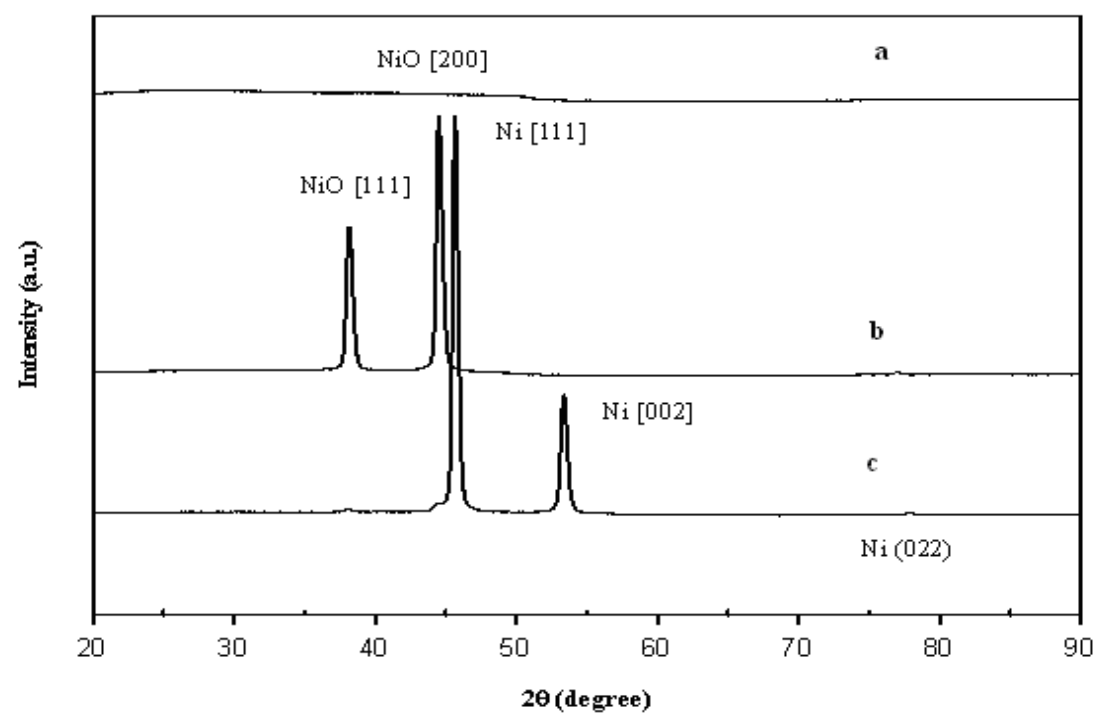

Figure 10. Wide-angle x-ray diffractometer (WAXD) diffraction patterns of: PVP/Ni acetate nanofibers (a), $\mathrm{NiO}$ nanofibers (b), and $\mathrm{Ni}$ nanofibers (c). 
Ag-coated Ni nanofibers prepared by the chemical coating of Ag yielded the WAXD pattern depicted in Figure 11. Low intensity peaks at about $39^{\circ}$ and $66^{\circ}$ were observed, corresponding to the Ag [111] and Ag [220] crystalline planes of cubic Ag. The high intensity peak at $\sim 46^{\circ}$ can be attributed to the $\mathrm{Ag}[200]$ and $\mathrm{Ni}[111]$ crystalline planes [22].

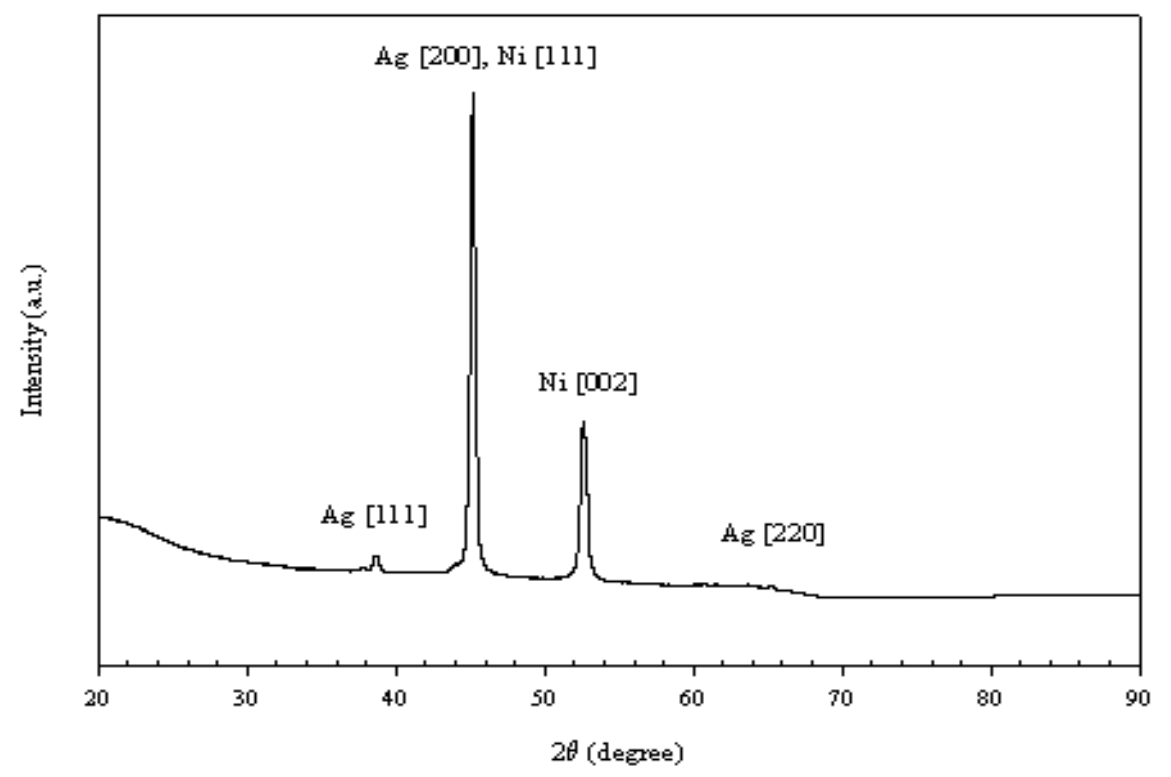

Figure 11. WAXD diffraction pattern for Ag-coated Ni nanofibers.

The $\rho_{\mathrm{v}}$ value of the as-prepared Ni nanofiber mat was approximately $4.2 \mathrm{~m} \Omega \cdot \mathrm{cm}$. Table 1 shows the comparison of $\rho_{\mathrm{v}}$ values with different conductive materials in the epoxy matrix. The $\rho_{\mathrm{v}}$ value for the Ag-coated short $\mathrm{Ni}$ nanofiber-epoxy nanocomposite was lower than the uncoated short $\mathrm{Ni}$ nanofiber-epoxy nanocomposite when using the same filler loading $(10 \mathrm{wt} \%)$. Furthermore, the $\rho_{\mathrm{v}}$ value for the epoxy nanocomposite could be reduced to, approximately, $0.0145 \Omega \cdot \mathrm{cm}$ by adding 40.3 $\mathrm{wt} \% \mathrm{Ni}$ nanofiber mat as filler in the composite.

Table 1. $\rho_{\mathrm{V}}$ values of epoxy nanocomposites filled with different kinds of conductive fibers.

\begin{tabular}{ccc}
\hline Sample & Dosage $(\mathbf{w t} \%)$ & Volume Resistivity $\mathbf{( \Omega \cdot c m )}$ \\
\hline Short Ni nanofiber filled-epoxy resin & 10 & 607 \\
Ag-coated short Ni nanofiber filled-epoxy resin & 10 & 173 \\
Ni nanofiber mat filled-epoxy resin & 40.3 & 0.0145 \\
\hline
\end{tabular}

\section{Conclusions}

Ni nanofibers were prepared successfully by using sol-gel processing and the elctrospinning technique. Initially, the nanofibers of PVP/Ni acetate composite were obtained, and some beaded nanofibers occurred with varying sizes of beads. Porous nanofibers of $\mathrm{NiO}$ were obtained subsequently with some beads after calcination. $\mathrm{NiO}$ nanofibers were densely packed due to the magnetic effect of $\mathrm{Ni}$ metal, even though some separate $\mathrm{NiO}$ nanofibers were also observed. The $\mathrm{NiO}$ nanofibers were reduced to Ni nanofibers with similar characteristics as $\mathrm{NiO}$ nanofibers, such as similar fiber diameters, brittleness, and beaded structure. The $\rho_{\mathrm{v}}$ of the as-prepared Ni nanofiber mat exhibited low values $(0.0145 \Omega \cdot \mathrm{cm}$ with $40.3 \mathrm{wt} \% \mathrm{Ni}$ nanofiber mat), thus providing great potential as conductive fillers in nanocomposite applications. The $\rho_{\mathrm{v}}$ value for Ag-coated Ni nanofiber-epoxy nanocomposite was lower than the uncoated Ni nanofiber-epoxy nanocomposite at the same filler loading due to the lower resistivity proportionally provided by the $\mathrm{Ag}$, as well as due to the oxidation protection by $\mathrm{Ag}$. 
Author Contributions: E.S. conceived the idea, constructed the methodology and finalized the current version of the manuscript; D.A. established the details of the methodology, performed the experiments, analyzed and documented the results and wrote the initial version of the manuscript. All authors have read and agreed to the published version of the manuscript.

Funding: This research received no external funding.

Acknowledgments: The authors would like to thank Darrell H. Reneker, Department of Polymer Science, The University of Akron, for providing the electrospinning apparatus and the high temperature furnace used in this work.

Conflicts of Interest: The authors declare no conflict of interest.

\section{References}

1. Sancaktar, E.; Aussawasathien, D. Nanocomposites of epoxy with electrospun carbon nanofibers: Mechanical behaviour. J. Adhes. 2009, 85, 160-179. [CrossRef]

2. Aussawasathien, D.; Sancaktar, E. Effect of non-woven carbon nanofiber mat presence on cure kinetics of epoxy nanocomposites. Macromol. Symp. 2008, 264, 26-33. [CrossRef]

3. Aussawasathien, D.; Sancaktar, E. Electrospun polyacrylonitrile-based carbon nanofibers and their silver modifications: Surface morphologies and properties. Curr. Nanosci. 2008, 4, 130-137. [CrossRef]

4. Viswanathamurthi, P.; Bhattarai, N.; Kim, D.; Lee, D.; Kim, S.; Morris, M. Preparation and morphology of niobium oxide fibres by electrospinning. Chem. Phys. Lett. 2003, 374, 79-84. [CrossRef]

5. Viswanathamurthi, P.; Bhattarai, N.; Kim, H.Y.; Cha, D.I.; Lee, D.R. Preparation and morphology of palladium oxide fibers via electrospinning. Mater. Lett. 2004, 58, 3368-3372. [CrossRef]

6. Shao, C.L.; Kim, H.Y.; Gong, J.; Ding, B.; Lee, D.R. A novel method for making silica nanofibres by using electrospun fibres of polyvinylalcohol/silica composite as precursor. Nanotechnology 2002, 13, 635-637. [CrossRef]

7. Shao, C.L.; Kim, H.Y.; Gong, J.; Ding, B.; Lee, D.R.; Park, S.J. Fiber mats of poly(vinyl alcohol)/silica composite via electrospinning. Mater. Lett. 2003, 57, 1579-1584. [CrossRef]

8. Guan, H.; Shao, C.; Wen, S.; Chen, B.; Gong, J.; Yang, X. A novel method for preparing Co3O4 nanofibers by using electrospun PVA/cobalt acetate composite fibers as precursor. Mate. Chem. Phys. 2003, 82, 1002-1006. [CrossRef]

9. Guan, H.; Shao, C.; Wen, S.; Chen, B.; Gong, J.; Yang, X. Preparation and characterization of NiO nanofibres via an electrospinning technique. Inorg. Chem. Comm. 2003, 6, 1302-1303. [CrossRef]

10. Rao, Y.K.; Rashed, A.H. Kinetics of reduction of nickel oxide with helium-hydrogen gas mixtures in the range 300-400 degrees C. Trans. Instn. Min. Metall. Sect. C Mineral Process Extr. Metall. 2001, 110, C1-C6.

11. Dilsiz, N.; Partch, R.; Matijevic, E.; Sancaktar, E. Silver coating of spindle- and filament- type magnetic particles for conductive adhesive applications. J. Adhe. Sci. Tech. 1997, 11, 1105-1118. [CrossRef]

12. Sancaktar, E.; Dilsiz, N. Thickness dependent conduction behavior of various particles for conductive adhesive applications. J. Adhe. Sci. Tech. 1999, 13, 763-771. [CrossRef]

13. Sancaktar, E.; Dilsiz, N. Pressure dependent conduction behavior of various particles for conductive adhesive applications. J. Adhe. Sci. Tech. 1999, 13, 679-693. [CrossRef]

14. Sancaktar, E.; Wei, Y. The effect of pressure on the initial establishment of conductive paths in electronically conductive adhesives. J. Adhe. Sci. Tech. 1996, 10, 1221-1235. [CrossRef]

15. Sancaktar, E.; Dilsiz, N. Anisotropic alignment of nickel particles in magnetic field for electronically conductive adhesives. J. Adhe. Sci. Tech. 1997, 11, 155-166. [CrossRef]

16. Sarkar, A.; Kapoor, S.; Yashwant, G.; Salunke, H.G.; Mukherjee, T. Preparation and characterization of ultrafine Co and Ni particles in a polymer matrix. J. Phys. Chem. B 2005, 109, 7203-7207. [CrossRef]

17. ASTM International. ASTM F43-99, Standard Test Methods for Resistivity of Semiconductor Materials (Withdrawn 2003); ASTM International: West Conshohocken, PA, USA, 1999.

18. Sancaktar, E.; Zhang, P. Nonlinear Viscoelastic Modeling of the Fiber Matrix Interphase in Composite Materials. J. Mech. Des. 1990, 112, 605-619. [CrossRef]

19. Shao, C.; Yang, X.; Guan, H.; Liu, Y.; Gong, J. Electrospun nanofibers of NiO/ZnO composite. Inorg. Chem. Comms. 2004, 7, 625-627. [CrossRef] 
20. Xiang, L.; Deng, X.Y.; Jin, Y. Experimental study on synthesis of NiO nano-particles. Sci. Mater. 2002, 47, 219-224. [CrossRef]

21. Fu, R.; Baumann, T.F.; Cronin, S.; Dresselhaus, G.; Dresselhaus, M.S.; Satcher, J.H., Jr. Formation of graphitic structures in cobalt- and nickel-doped carbon aerogels. Langmuir 2005, 21, 2647-2651. [CrossRef]

22. He, R.; Qian, X.; Yin, J.; Zhu, Z. Preparation of polychrome silver nanoparticles in different solvents. J. Mater. Chem. 2002, 12, 3783-3786. [CrossRef]

(C) 2020 by the authors. Licensee MDPI, Basel, Switzerland. This article is an open access article distributed under the terms and conditions of the Creative Commons Attribution (CC BY) license (http://creativecommons.org/licenses/by/4.0/). 